\title{
Efektivitas Pendekatan Impact Counseling Untuk Meningkatkan Resiliensi Siswa Korban Bully Pada Kelas VIII-B dan VIII-C SMP Muhammadiyah 22 Kisaran Tahun 2018
}

\author{
Rafael Lisinus Ginting, M.Pd \\ Retno Widiastuty \\ Jurusan Bimbingan dan Konseling, FIP \\ Universitas Negeri Medan
}

\begin{abstract}
Abstrak
Penelitian ini bertujuan melihat efektivitas pendekatan impact counseling untuk meningkatkan resiliensi siswa korban bully di SMP Muhammadiyah 22 Kisaran.Jenis penelitian ini adalah quasi experimental design.Desain yang digunakan dalam penelitian ini adalah menggunakan non- equivalent countrol group design. Memiliki instrumen yang terdiri dari 40 item dengan tingkat reliabilitas yaitu R11=0,696 dengan kategori sedang. Teknik analisis data yang digunakan dalam penelitian ini adalah dengan menggunakan uji $t$ untuk melihat perbedaan pada kedua kelompok antara kelompok eksperimen dan kelompok kontrol.Pengumpulan data yang digunakan dalam penelitian ini adalah dengan menggunakan angket resiliensi siswa. Hasil uji menunjukkan bahwa skor pre-test pada kelompok ekperimen diperoleh rata- rata sebesar 75 dan sedangkan skor post-test diperoleh rata - rata sebesar 136.5 dengan selisih 61.5 atau $82 \%$. Hasil pre-test pada kelompok kontrol diperoleh rata-rata sebesar 76 sedangkan skor post-test diperoleh rata - rata sebesar 92 dengan selisih 25 atau 21\%, artinya $136.5>92$ atau $82 \%>21 \%$. Hasil analisis uji $t$ pada kelompok ekperimen dan kelompok kontrol menunjukkan bahwa $t_{\text {hitung }}>t_{\text {tabel }}(3.65>2.92$ ). Berarti ada perbedaan diantar kedua kelompok dan pendekatan impact counseling efektif untuk meningkatkan resiliensi siswa korban bully pada Kelas VIII-B dan VIII-C di SMP Muhammadiyah 22 Kisaran T.A 2017/2018.
\end{abstract}

Kata Kunci :Impact Couseling ; Resiliensi ; Korban Bully

\section{PENDAHULUAN}

Sekolah merupakan lembaga pendidikan formal yang secara sistematis melaksanakan program bimbingan, pengajaran, dan latihan dalam rangka membantu siswa agar mampu mengembangkan potensinya, baik yang menyangkut aspek moral, spiritual, intelektual, emosional, maupun social (Yusuf,2001). Oleh karena itu suasana yang nyaman dan tenang di sekolah sangat ditekankan agar siswa betah berada di sekolah sehingga dapat menimba ilmu dengan baik.

Namun, akhir-akhir ini banyak kasus yang mencoreng dunia pendidikan di Indonesia baik kasus yang dilakukan oleh tenaga pendidik maupun anak didiknya. Kasus yang mencoreng dunia pendidikan di Indonesia salah satunya adalah tindakan agresif yang disengaja, dilakukan berulang-ulang dan dari waktu ke waktu, dan terdapat ketidakseimbangan kekuasaan atau kekuatan yang membuat orang lain takut atau merasa terancam dan dilakukan oleh pendidik kepada siswa maupun antar siswa itu sendiri. Hal ini disebut juga dengn istilah perundungan atau bully.

Dampak paling fatal akibat bully ini adalah berupa tindakan bunuh diri. Namun pada umumnya tidak, banyak 
korban bully yang masih bertahan hidup walau harus menanggung luka batin. Pada siswa usia sekolah korban bully dapat mengalami trauma, phobia sekolah, tidak percaya diri, pemurung, pendiam, penakut, tertutup, prestasi menurun, dan lain sebagainya.

Siswa yang mengalami bullying, mungkin saja nampak mampu mengatasinya tetapi dalam konsep resiliensi, kemampuan anak untuk menjadi tangguh (resilience) bersifat fluktuatif dari satu ke lain waktu.Anakanak yang mengalami bullying dan nampak resilien menghadapi permasalahan tersebut terlihat dalam perilakunya yang tidak bermasalah, boleh jadi sesungguhnya masih bergulat dengan inner distress dalam diri mereka.

Menurut Jackson (dalam Astika, 2016) resiliensi adalah kemampuan individu untuk dapat beradaptasi dengan baik meskipun dihadapkan dengan keadaan yang sulit.Reliensi juga merupakan kemampuan seseorang untuk menyesuaikan diri dan bangkit dari keterpurukan. Resiliensi dapat memotivasi korban bully untuk tidak putus asa dan tidak menyangkal. Resiliensi dapat membuat mereka, korban bully, untuk dapat menghindari dampak yang tidak menyenangkan dan mungkin bahkan dapat melaluinya dengan
baik.Resiliensi juga mendorong korban bully untuk menjadikan pengalaman mereka untuk berubah ke arah yang lebih positif.

Berdasarkan beberapa penelitian terdapat dampak yang negatif apabila korban bullymemiliki resiliensi rendah. Siswa yang menjadi korban bully yang memiliki resilien rendahakan cenderung menunjukkan ketidakbahagian yang lebih besar dibandingkan siswa lain (Fekkes, Pijpers, dan Verloove-Vanhorick, 2004; Jankauskiene, Kardelis, Sukys, dan Kardeliene, 2008; Matos dan Carvalhosa, 2001).

Dalam menghadapi fakta di atas, jika hal ini dibiarkan dengan tidak ada solusi dan bantuan dari sekolah dan siswa yang menjadi korban bully tidak memperoleh bantuan dan penanganan yang semestinya, bukan tidak mungkin siswa akan berkembang menjadi pribadi yang pendiam, tetutup, kurang percaya diri, tidak memiliki sikap optimis dan sebagainya.

Dalam dunia pendidikan, beberapa hal yang dapat dijadikan sebagai satu solusi agar siswa siswa korban bullymampu lepas dari efek yang ditimbulkan pengalaman menjadi korban bully ini adalah melalui pendekatan bimbingan konseling. Menurut Yusuf (2008)bimbingan konseling merupakan 
sebuah proses bantuan yang diberikan kepada siswa agar mereka mampu mengembangkan dirinya secara optimal.

Dalam bimbingan dan konseling terdapat konseling kreatif yang menurut Gladding (dalam Rahmadian, 2011:2) merupakan proses konseling yang membutuhkan kreativitas didalamnya yang mampu membuat klien merasa nyaman dengan tahapan pelaksanaan konseling,terciptanya suasana yang aman dan mendukung sehingga klien mampu secara kreatif mengkaji masalah, membangun perspektif alternatif terhadap masalah, serta menghasilkan dan mengevaluasi beragam pilihan solusi.Dalam konseling kreatif ini terdapat pendekatan impact konseling. Menurut Jacob (dalam Rahmadian, 2011:5) pendekatan impact couseling merupakan pendekatan dalam konseling yang menghargai ragam cara belajar, cara berubah, dan cara berkembang konseli yang dalam prosesnya, konselor menggunakan pendekatan multisensory.

\section{KAJIAN PUSTAKA}

\section{Resiliensi Korban Bully}

Resiliensi korban bully dapat diartikan sebagai kemampuan seseorang yang mengalami tindakan bullydalam mengatasi perlakuan yang tidak menyenangkan dalam kondisi dan situasi yang penuh tekanan untuk bangkit dari keterpurukan, serta menyelesaikan permasalahan tanpa menggunakan kekerasan.

Adapun Reivich dan Shatte (2002) membagi 7 aspek kemampuan yang menunjukkan resilensi pada seseorang, yaitu regulasi emosi, pengendalian impuls, optimisme, empati, analisis kausal, self efficacy dan reaching out.

Faktor yang mempengaruhi resiliensi meliputi dukungan eksternal dan sumber-sumbernya yang ada pada diri seseorang (misalnya keluarga, lembaga-lembaga pemerhati dalam hal ini yang melindungi siswa), kekuatan personal yang berkembang dalam diri seseorang (seperti self-esteem, acapacityforselfmonitoring, spritualitas dan altruism), dan kemampuan sosial (seperti mengatasi konflik, kemampuankemampuan berkomunikasi).Grotberg (1995), mengemukakan faktor-faktor resiliensi yang diidentifikasikan berdasarkan sumber-sumber yang berbeda. Untuk kekuatan individu dalam diri pribadi digunakan istilah ' $I A m$ ', untuk dukungan eksternal dan sumbersumbernya digunakan istilah 'IHave', sedangkan istilah 'ICan' digunakan untuk kemampuan interpersonal.

\section{Impact Counseling}

Menurut Jacob (dalam Rahmadian, 2012) impactcounseling merupakan 
pendekatan dalam konseling kreatif yang menghargai ragam cara belajar, cara berubah, dan cara berkembang konseli. Pendekatan ini menekankan pada pentingnya membantu konseli untuk memahami permasalahan dan solusi permasalahan secara jelas dan konkrit.

Pendekatan impactcounseling menekankan pendekatan multisensori yang melibatkan dimensi verbal, visual, dan kinestetik dalam proses konseling.

\section{Pendekatan Impactcounseling} merupakan pendekatan yang unik dalam konseling yang berupaya mengintegrasikan berbagai konsep dalam rationalemotivebehaviortherapy (REBT), transactionalanalysis (TA), gestalt, dan realitytherapy dengan penggunaan berbagai properti, gambar, dan gerak dalam proses konseling. Proses konseling dalam impactcounseling menekankan keaktifan konseli dalam berpikir, memahami, dan mengalami sesi konseling.

Menurut Jacob (dalam

Rahmadian,

implementasipendekatan

impactcounseling mengandung empat karakteristik yaitu :

a. Multisensori yang berkaitan dengan upaya mengkongkritkan ide - ide abstrak secara visual, penggunaan konseling eksperensial, serta penerapan aspek kinestetik dalam konseling.

b. Karakteristik motivasional merujuk pada kemampuan konselor memotivasi konseli untuk berubah melewati tahap-tahap perubahan yang mencakup tahap prekontemplasi, kontemplasi, persiapan (preparation), tindakan (action), pemeliharaan (maintenance), dan terminasi.

c. Karakteristik marketing berkaitan dengan upaya konselor untuk membuat sesi konseling menjadi lebih menarik dan efektif sehingga konseli merasakan manfaat nyata selama sesi konseling serta bersedia melakukan perubahan yang perlu dilakukan.

d. Karakteristik maps yang merujuk pada tahap atau peta jalan yang perlu dilalui konselor selama sesi konseling.

Menurut Jacob (dalam Rahmadian, 2011:6) tahapan dalam impactcounseling yaitu:

a. Fase rapport menunjukkan fase membangun hubungan yang genuine dan saling percaya antara konselor dan konseli.

b. Fase Contract merujuk pada persetujuan baik secara implisit ataupun eksplisit antara konselor dan 
konseli dalam menetapkan tujuan seluruh sesi konseling atau sebagian sesi konseling.

c. Fase Focus merujuk pada tahapan yang berfokus pada topik tertentu atau isu tertentu dalam jangka waktu tertentu

d. Fase Funnel merujuk pada tahap mendiskusikan sebuah isu dengan cara tertentu sampai tercapai tingkat pemahaman (insight) baru yang lebih dalam.

e. Fase penutupan yang merupakan fase dimana konseli merangkum apa yang telah ia pelajari dan membicarakan bagaimana konseli akan menggunakan informasi yang diperolehnya setelah sesi konseling berakhir.

\section{METODE PENELITIAN}

Jenis penelitian yang digunakan adalah penelitian quasi experimental design.Penelitian quasi experimental design adalah penelitian yang dilakukan tanpa randomisasi, namun masih menggunakan kelompok kontrol.Pendekatan yang digunakan dalam penelitian ini adalah pendekatan kuantitatif.Desain yang digunakan dalam penelitian ini adalah menggunakan nonequivalent countrol group design.

Populasi pada penelitian ini adalah seluruh siswa kelas VIII-B dan VIII-C
SMP Muhmmadiyah 22 Kisaran T.A 2017/2018 yang berjumlah 60 siswa.Penentuan sampel pada penelitian ini ditentukan secara teknik penentuan sampel yang digunakan adalah samplingpurposive. Sehingga akhirnya dapat diidentifikasi 4 orang sebagai siswa korban bully yang memiliki resiliensi rendah di sekolah.

Teknik pengumpulan data yang digunakan dalam penelitian ini observasi dan angket.Penggunaan angket untuk mengukur tingkat resiliensi siswa korban bully, sedangkan obsevasi untuk mengamati siswa korban bully.

Adapun angket yang digunakan dalam penelitian ini bepedoman pada skala Likert, pernyataan pada skala tersebut memiliki dua sifat yaitu favourable (positif) dan unfavorable (negative). Setiap pernyataan memiliki 4 alternatif jawaban yaitu Sangat Sering (SS), Sering (S), Kadang-kadang (KK) dan Tidak Pernah (TP). Untuk pernyataan yang bersifat favourabel diberi rentangan nilai 4-1 dan yang bersifat unfavorable diberi rentangan nilai 1-4. Jumlah item pernyataan sebanyak 40 item dengan rhitung $>$ rtabel yaitu $=0,412>0,361$, serta hasil perhitungan reliabilitas angket dengan menggunakan rumus alpha, $\mathbf{r} 11=$ 0,695 . 


\section{HASIL PENELITIAN DAN}

\section{PEMBAHASAN}

Setelah dilakukan penyebaran angket, maka dapat diketahui gambaran per-indikator resiliensi siswa korban bully, seperti pada tabel di bawah ini.

Tabel 1. Gambaran per-Indikator Resiliensi Siswa Korban Bully

\begin{tabular}{|c|c|c|c|c|c|c|c|c|}
\hline \multirow{2}{*}{ Indikator } & \multicolumn{2}{|c|}{ R1 } & \multicolumn{2}{l|}{ R2 } & \multicolumn{2}{l|}{ R3 } & \multicolumn{2}{l|}{ R4 } \\
\cline { 2 - 9 } & Skor & Kategori & Skor & Kategori & Skor & Kategori & Skor & Kategori \\
\hline $\begin{array}{c}\text { Regulasi } \\
\text { Emosi }\end{array}$ & 13 & Rendah & 14 & Sedang & 15 & Sedang & 15 & Sedang \\
\hline $\begin{array}{c}\text { Pengendali } \\
\text { an Implus }\end{array}$ & 7 & Rendah & 6 & Rendah & 6 & Rendah & 10 & Sedang \\
\hline Optimisme & 17 & Rendah & 19 & Rendah & 19 & Rendah & 20 & Sedang \\
\hline $\begin{array}{c}\text { Analisa } \\
\text { Kausal }\end{array}$ & 13 & Rendah & 14 & Sedang & 11 & Rendah & 11 & Rendah \\
\hline Empati & 7 & Rendah & 6 & Sedang & 5 & Rendah & 5 & Rendah \\
\hline $\begin{array}{c}\text { Self- } \\
\text { Eficacy }\end{array}$ & 10 & Sedang & 9 & Rendah & 11 & Sedang & 8 & Rendah \\
\hline $\begin{array}{c}\text { Reaching } \\
\text { Out }\end{array}$ & 9 & Sedang & 9 & Sedang & 14 & Tinggi & 8 & Rendah \\
\hline
\end{tabular}

Tabel 2 Analisa Data Pre-Test Dan Post-

Test Kelompok Ekspeimen

\begin{tabular}{|c|c|c|c|c|c|}
\hline No & Responden & $\begin{array}{c}\text { Skor } \\
\text { Pre-test }\end{array}$ & $\begin{array}{c}\text { Skor } \\
\text { Post-test }\end{array}$ & Skor Perubahan & $\begin{array}{c}\text { Persentase } \\
\%\end{array}$ \\
\hline 1 & 1 & 73 & 142 & 69 & $48 \%$ \\
\hline 2 & 2 & 77 & 131 & 54 & $41 \%$ \\
\hline Jumlah & 150 & 273 & 123 & $82 \%$ \\
\hline \multicolumn{2}{|c|}{ Rata-rata } & 75 & 136.5 & 61.5 & $82 \%$ \\
\hline
\end{tabular}

Berdasarkan tabel di atas dapat diketahui selisih perubahan skor resiliensi siswa korban bully pada kelompok eksperimen sebagai berikut :

Resiliensi siswa korban bully responden 1 memiliki skor pre-test (sebelum diberi Pendekatan impact counseling) sebesar 73 dengan kategori rendah dan skor post-test (setelah diberi pendekatan impact counseling) sebesar
142 dengan kategori tinggi. Dengan demikian siswa responden 1 mengalami peningkatan resiliensi sebesar 69 atau $48 \%$

Resiliesnsi siswa korban bully responden 2 memiliki skor pre-test (sebelum diberi pendekatan impact counseling) sebesar 77 dengan kategori rendah dan skor post-test (setelah diberi pendekatan impact counseling) sebesar 131 dengan kategori sedang. Dengan demikian siswa responden 2 mengalami peningkatan resiliensi sebesar 54 atau $41 \%$.

Tabel 3. Analisa Data Pre-Test Dan Post-

\section{Test Kelompok Kontrol}

\begin{tabular}{|c|c|c|c|c|c|}
\hline No & Responden & $\begin{array}{c}\text { Skor } \\
\text { Pre-test }\end{array}$ & $\begin{array}{c}\text { Skor } \\
\text { Post-test }\end{array}$ & Skor Perubahan & Persentase \\
$\%$ \\
\hline 1 & 3 & 77 & 84 & 7 & $8.3 \%$ \\
\hline 2 & 4 & 75 & 100 & 25 & $25 \%$ \\
\hline \multicolumn{2}{|c|}{ Jumlah } & 152 & 184 & 32 & $21 \%$ \\
\hline \multicolumn{2}{|c|}{ Rata-rata } & 76 & 92 & 16 & $21 \%$ \\
\hline
\end{tabular}

Berdasarkan tabel di atas dapat diketahui selisih perubahan skor resiliensi siswa korban bully pada kelompok kontrol sebagai berikut :

Resiliensi siswa korban bully responden 3 pada kelompok konrol memiliki skor pre-test (sebelum diberi layanan konsling individual secara konvensional) sebesar 75 dengan kategori rendah dan skor post-test (setelah diberi 
layanan) sebesar 84 dengan kategori rendah. Dengan demikian siswa responden 3 mengalami resiliensi yang tetap sebesar 7 atau $8.3 \%$.

Resiliensi siswa korban bully responden 4 pada kelompok kontrol memiliki skor pre-test (sebelum diberi layanan konsling individual secara konvensional) sebesar 75 dengan kategori rendah dan skor post-test (setelah diberi layanan) sebesar 100 dengan kategori rendah. Dengan demikian siswa responden 4 mengalami resiliensi yang tetap sebesar 25 atau $25 \%$.

Selisih skor perubahan pre-test dan post-test kelompok eksperimen dan kelompok kontrol

Tabel 5. Selisih Skor Perubahan Kelompok

Ekperimen Dan Kelompok Kontrol

\begin{tabular}{|c|c|c|l|}
\hline & $\begin{array}{c}\text { Skor perubahan } \\
\text { kel.eks }\end{array}$ & $\begin{array}{c}\text { Skor perubahan } \\
\text { kel.kontrol }\end{array}$ & \multicolumn{1}{|c|}{ Sel. } \\
\hline 1 & $69(48 \%)$ & $7(8.3 \%)$ & $62(39.7 \%)$ \\
\hline 2 & $54(41 \%)$ & $25(25 \%)$ & $29(16 \%)$ \\
\hline Jumlah & $123(82 \%)$ & $32(21 \%)$ & $91(61 \%)$ \\
\hline Rata-rata & $61.5(82 \%)$ & $16(21 \%)$ & $45.5(61 \%)$ \\
\hline
\end{tabular}

Berdasarkan tabel selisih skor perubahan dan selisih persentase pada kelompok eksperimen dan kelompok kontrol sebagai berikut:

1. Responden 1 memiliki skor perubahan 69 yang persentasinya 48 $\%$ dibandingkan dengan skor kelompok kontrol yang memiliki skor 7 dengan persentasi $8.3 \%$ maka ditemukanlah selisih diantar kedua kelompok pada responden pertama sebanyak 62 dengan persentasi 39.7 $\%$.

2. Responden 2 memiliki skor perubahan 54 yang persentasinya 41 $\%$ dibandingkan dengan skor kelompok kontrol yang memiliki skor 25 dengan persentasi $25 \%$ maka ditemukanlah selisih diantar kedua kelompok pada responden kedua sebanyak 62 dengan persentasi $16 \%$.

Maka dapat dilihat jumlah selisih pada kedua kelompok 91 dan memiliki rata - rata 45.5 dengan persentasi $61 \%$.

\section{Pengujian Hipotesis}

Berdasarkan perhitungan diatas, $\mathrm{dk}=$ 2 dan taraf nyata $\alpha=0,05$ dan $\mathrm{t}(1-\alpha)=$ $\mathrm{t}_{(0,95)}$ diperoleh $\mathrm{t}_{\text {tabel }}=2,92$ dan $\mathrm{t}_{\text {hitung }}=$ 3.65. Berdasarkan perhitungan diperoleh $t_{\text {hitung }}$ lebih besar dari $t_{\text {tabel. Jadi dapat }}$ disimpulkan bahwa ada perberbedaan dari kelompok ekperimen dan kelompok kontrol untuk meningkatkan resiliensi siswa korban bully di SMP Muhammadiyah 22 Kisaran.

\section{Pembahasan}

Sebelum dilaksanakan pendekatan impact counseling untuk meningkatkan 
resiliensi siswa korban bully tergolong dalam kategori rendah. Hal ini dibuktikan dari hasil angket dimana skor siswa korban bully menunjukkan rata - rata kategori rendah. Dalam hal ini peneliti menggunakan pendekatan impac counseling untuk mengatasi hal tersebut, dengan pendakatan impact counseling siswa akan lebih fokus terhadap solusi penyelesain masalah mereka karena pelaksanaan pendekatan impact counseling menekankan kekreativitasan konselor untuk menggunakan alat - alat yang mengumpakan alat tersebut adalah diri klien atau masalah klien sehingga sesi konseling lebih menarik dan efektif dan konseli dapat merasakan manfaat selama sesi konseling.

Berdasarkan selisih skor perubahan pada kelompok eksperimen pada responden 1 memiliki skor perubahan 69 yang persentasinya $48 \%$ dibandingkan dengan skor kelompok kontrol yang memiliki skor 7 dengan persentasi $8.3 \%$ maka ditemukanlah selisih diantar kedua kelompok pada responden pertama sebanyak 62 dengan persentasi $39.7 \%$. Selisih skor perubahan kelompok eksperimen pada responden 2 memiliki skor perubahan 54 yang persentasinya 41 $\%$ dibandingkan dengan skor kelompok kontrol yang memiliki skor 25 dengan persentasi $25 \%$ maka ditemukanlah selisih pada responden 2 sebanyak 62 dengan persentasi $16 \%$ diantar kelompok eksperimen dan kelompok kontrol.

Hasil penelitian ini sesuai dengan pendapat Gladding (dalam Rahmadian, 2011:2) pendekatan impact counseling memiliki tujuan untuk mencerahkan klien membantu konseli mengembangkan kreatifitas yang dalam pelaksanaannya menekankan pendekatan multisensori dengan melibatkan dimensi verbal, visual, dan kinestetik. Menurut hasil penelitian, subjek penelitian menunjukkan perubahan resiliensi siswa korban bully menjadi lebih baik setelah diberi pendekatan impact counseling, sesuai dengan tujuan pendekatan impact counseling yang diungkapkan Gladding (dalam Rahmadian, 2011:2) jumlah selisih skor sebanyak 91 dengan persentasi $\quad 61 \%$ pada kelompok eksperimen dan kelompok kontrol.

\section{PENUTUP}

\section{Kesimpulan}

Berdasarkan pelaksanaan impact counseling pada kelompok eksperimenperubahan yang paling menonjolpada responden 1 memiliki masalah di regulasi emosi, pengendalian implus, optimisme, analisa kausal dan empati kategori tinggi dengan skor 25,18, 34, 23 dan 10 yang memiliki perubahan skor $48 \%$, responden 2 memiliki masalah 
di pengendalian implus, optimisme dan self-eficacy kategori tinggi dengan skor 17, 22, dan 16 yang memiliki perubahan skor $41 \%$.

Hasil perubahanpada kelompok kontrol, diperoleh data sebagai berikut : responden 3 memiliki masalah di pengendalian implus, optimisme, analisa kausal dan empati kategori rendah dengan skor $8,20,15$ dan 7 yang memiliki perubahan skor $8.3 \%$, Responden 4 memiliki masalah di analisa kausal, empati, self-eficacy dan reaching out kategori rendah dengan skor 11, 10, 10, dan 9 yang memiliki perubahan skor $25 \%$.

Kelompok ekperimen memiliki perubahan dari yang rendah berubah menjadi tinggi, dapat disimpulkan bahwa pendekatan impact counseling efektif untuk meningkatkan resiliensi siswa korban bully pada kelas VIII-B dan VIIIC di SMP Muhammadiyah 22 Kisaran T.A 2017/2018.

\section{Saran}

Berdasarkan kesimpulan di atas, maka sebagai tindak lanjut penelitian ini disarankan hal-hal sebagai berikut :

Bagi siswa : diharapkan bagi siswa penelitian ini dapat membantu untuk meningkatkan resiliensi siswa korban bully.
Bagi Guru BK : diharapkan guru BK SMP Muhammadiyah 22 Kisaran, pendekatan impact counseling ini dapat bermanfaat untuk mempermudah guru BK dalam membina siswa yang menjadi korban bully untuk membentuk kepribadian yang lebih baik, yang lebih percaya diri dalam berinteraksi dengan orang lain dan diharapkan kepada guru BK SMP muhammadiyah 22 kisaran lebih memperhatikan siswa yang menjadi korban bully di sekolah

Bagi peneliti lain : diharapkan bagi peneliti lain dapat dijadikan sebagai bahan masukan dan sumber referensi dalam penelitian di bidang yang sama terutama untuk meningkatkan resiliensi siswa.

\section{DAFTAR PUSTAKA}

Dewi. 2016. Resiliensi Anak Korban Bullying di Sekolah. Surakarta: Universitas Muhammadiyah Surakarta. Disertasi tidak diterbitkan.

Gladding. 2011. Using Creativity and the Creative Arts in Counseling: An International Approach. Turkish Psychological Counseling and Guidance Journal, 4 (35), 1-7.

Halimah, dkk. 2015. Persepsi pada Bystander terhadap Intensitas Bullying pada Siswa SMP. 
Makassar. Jurnal Psikologi, 42, 129 -140 .

Hidayati. 2012. Bullying pada Anak: Analisis dan Alternatif Solusi. INSAN, 14, 41-48.

Rahmadian. 2012. Prosiding International Seminar \&Workshop Post Traumatic Counseling. STAIN Batusangkar.
Reivich, K \& Shatte, A. 2002.The resilience Factor ; 7 Essential Skill For Overcoming Life's Inevitble Obstacle. New York. Broadway Book.

Sugiyono. (2016). Metode Penelitian Kuantitatif, Kualitatif dan $R \& D$. Bandung: Alfabet 